\title{
Shared medical appointments as a new model for carpal tunnel surgery consultation: A randomized clinical trial
}

\author{
Alison L Wong MD¹, Janet Martin BSc${ }^{2}$, Michael J Wong MD³, Michael Bezuhly MD MSc${ }^{1}$, David Tang MD ${ }^{1}$
}

\begin{abstract}
AL Wong, J Martin, MJ Wong, M Bezuhly, D Tang. Shared medical appointments as a new model for carpal tunnel surgery consultation: A randomized clinical trial. Plast Surg 2016;24(2):107-112.
\end{abstract}

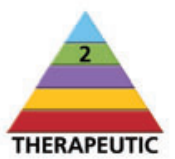

BACKGROUND: In chronic disease management, shared medical appointments have been shown to improve clinic access, productivity and patient education. However, adoption of this model in surgical consultation is limited, and its effect on surgical patients' satisfaction, comfort and surgical risk recall is unknown.

OBJECTIVE: To determine whether shared medical appointments could be applied to carpal tunnel surgery consultation while being equally effective as individual consultation for risk recall, patient comfort and satisfaction.

METHODS: A prospective randomized trial involving 80 patients referred for carpal tunnel release consultation, in which patients were assigned to an educational discussion individually or as part of a shared appointment, was conducted. In a blinded fashion, patients were contacted preoperatively to assess their risk recall and postoperatively to rate their overall satisfaction, comfort and satisfaction with the surgeon.

RESULTS: Patient demographics were equal. Surgical risk recall was equivalent between shared and individual consults $(2.06 \pm 1.15$ versus $1.64 \pm 1.04 ; \mathrm{P}=0.11)$. More participants in the shared appointments condition remembered the specific risks of infection $(61.1 \%$ versus $33.3 \%$; $\mathrm{P}=0.020)$ and bleeding $(30.6 \%$ versus $10.3 \% ; \mathrm{P}=0.028)$. There was no difference in overall satisfaction ( 8.70 versus $8.88 ; \mathrm{P}=0.75)$, satisfaction with the surgeon ( 8.05 versus $8.13 ; \mathrm{P}=0.92$ ) or overall comfort ( 8.80 versus 8.31 ; $\mathrm{P}=0.46$ )

DISCUSSION: Shared medical appointments for carpal tunnel surgery consultation were equivalent to individual consultation in terms of surgical risk recall, patient satisfaction and comfort.

CONCLUSION: These results support the use of shared appointments for large-volume, low-variation surgery.

Key Words: Carpal tunnel; Health care delivery; Health management; Patient education; Risk recall; Shared medical appointment
Les rendez-vous médicaux groupés comme nouveau modèle de consultation avant une chirurgie du canal carpien : un essai aléatoire et contrôlé

HISTORIQUE : Dans la prise en charge des maladies chroniques, les rendez-vous médicaux groupés améliorent l'accès aux cliniques, la productivité et l'éducation des patients. Cependant, ce modèle est peu utilisé en consultation chirurgicale, et on n'en connaît pas l'effet sur la satisfaction des patients en voie d'être opérés, leur confort et leurs souvenirs des risques de la chirurgie.

OBJECTIF : Déterminer si les rendez-vous médicaux groupés peuvent être utilisés dans le cadre des consultations avant une chirurgie du canal carpien avec la même efficacité qu'une consultation individuelle sur le plan des souvenirs des risques, du confort et de la satisfaction des patients.

MÉTHODOLOGIE : Les chercheurs ont réalisé un essai aléatoire et prospectif auprès de 80 patients dirigés vers une consultation en vue d'une libération du canal carpien. Les patients ont été affectés à une séance d'éducation individuelle ou à un rendez-vous groupé. À l'aveugle, on a communiqué avec les patients avant l'opération pour évaluer leurs souvenirs des risques et après l'opération pour déterminer leur satisfaction et leur confort globaux ainsi que leur satisfaction envers le chirurgien.

RÉSULTATS : Les patients avaient une démographie similaire. Leurs souvenirs des risques de la chirurgie étaient similaires dans les consultations groupées ou individuelles $(2,06 \pm 1,15$ par rapport à $1,64 \pm 1,04 ; \mathrm{P}=0,11)$. Plus de patients des consultations groupées se souvenaient des risques spécifiques d'infection $(61,1 \%$ par rapport à $33,3 \% ; \mathrm{P}=0,020)$ et de saignements $(30,6 \%$ par rapport à 10,3\%; $\mathrm{P}=0,028)$. Il n'y avait pas de différence dans la satisfaction globale $(8,70$ par rapport à 8,$88 ; \mathrm{P}=0,75)$, la satisfaction envers le chirurgien $(8,05$ par rapport à 8,$13 ; \mathrm{P}=0,92)$ ou le confort global $(8,80$ par rapport à 8,$31 ; \mathrm{P}=0,46)$.

EXPOSÉ : Les rendez-vous médicaux groupés lors des consultations en vue d'une chirurgie du canal carpien étaient équivalents aux consultations individuelles pour ce qui est du souvenir des risques chirurgicaux, de la satisfaction des patients et du confort.

CONCLUSION : Ces résultats appuient l'utilisation des rendez-vous groupés pour les opérations peu variables et à grand volume.
Tnitial consultation and patient education are essential components of a clinic visit; however, they require a significant portion of time from both surgeon and patient. Effective informed consent provides patients with more realistic expectations, increases cooperation and results in higher satisfaction (1-4). In comparison, poor clinician communication and inadequate understanding of possible risks are common reasons for patients to seek legal action (5).

Ideally, the education process allows adequate time for patients to receive ample information, and for their questions to be answered satisfactorily. However a considerable amount of time is required for sufficiently comprehensive informed consent discussions, and generally comes at the expense increased clinic wait times (6). Worse yet, despite education through the traditional consultation model, patients are often unable to recall the specific risks that are discussed with their surgeon (7-9).

Shared medical appointments (SMAs, also known as 'group visits' or 'group consultations') provide an alternative format to individual consultation for patient education. This model can increase the length of time patients receive education about their procedure, and they are also able to discuss the procedure with others who are undergoing the same surgery. The additional benefit is that the total time to see the same number of patients is reduced compared with multiple individual appointments, which results in improved clinic flow and increased access for patients (10-13). Despite provider concerns of patients' reluctance and potential privacy issues, patients consistently report high levels of satisfaction and willingness to participate in future

${ }^{1}$ Division of Plastic $\mathcal{E}$ Reconstructive Surgery; ${ }^{2}$ Faculty of Medicine; ${ }^{3}$ Department of Anesthesia, Dalhousie University, Halifax, Nova Scotia

Correspondence: Dr David Tang, Division of Plastic $\mathcal{E}$ Reconstructive Surgery, Room 4714, Halifax Infirmary Site, QEII Health Sciences

Centre, 1796 Summer Street, Halifax, Nova Scotia B3H 3A7. Telephone 902-473-1740, fax 902-473-6296, e-mail dt.tang@dal.ca 


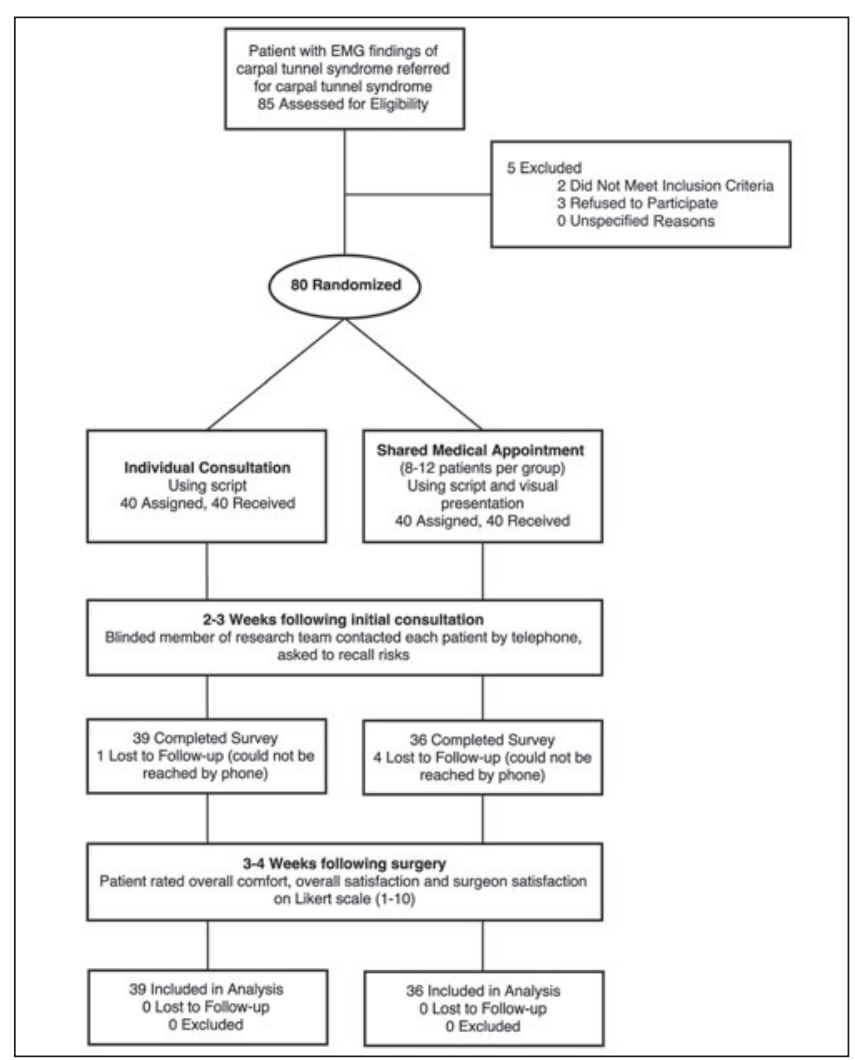

Figure 1) Flow diagram of study design and patient enrollment methods. Patients who could not be contacted for their initial phone survey were not included in the analysis. EMG Electromyography

SMAs (11,14-17). SMAs are now implemented in internal medicine, neurology and some low-variation surgeries, but there has not yet been an evaluation of whether SMAs impact surgical risk recall $(11,12,17$ 20). Additionally, many previous studies have not included an assessment of patients' satisfaction and comfort with the process and their provider, despite the significant impact these factors have on patients' perception of the quality of care delivered (4).

Carpal tunnel release (CTR) is an ideal surgery to test the effectiveness of the SMA format because it is a relatively standardized procedure with well-established risks and complications (21-23). It is also very common, with an estimated 400,000 to 500,000 cases in the United States annually (21). In addition, carpal tunnel syndrome is a minimally stigmatizing disease according to the Weiss model of medical stigma. This reduces patients' discomfort participating in a discussion that would disclose their diagnosis (24).

An SMA program for patients scheduled to undergo CTR was implemented at a public referral hospital outpatient plastic surgery clinic. Following their initial consultation, patients' recall of surgical risks was evaluated because it is an established measure to assess memory of the informed consent process $(5,8,25,26)$. In follow-up, patients were asked to rate their comfort and satisfaction. It was hypothesized that SMAs would not reduce patients' ability to recall surgical risks or decrease their satisfaction or comfort compared with individual consultation.

\section{METHODS}

Study design and patient sample

This was a prospective study of 80 patients with moderate to severe carpal tunnel syndrome confirmed by electrodiagnostic studies referred for open CTR consultation at a single institution by a single surgeon (DT). Figure 1 depicts the patient assignment and timeline. Exclusion criteria were: unconfirmed carpal tunnel syndrome; age $<16$ years; poor English fluency; discussion of additional procedures; previous open (not percutaneous) hand surgery; and inability to provide informed consent $(7,25)$. Of 85 patients screened for eligibility, two did not meet the inclusion criteria (previous open hand surgery) and three declined participation in a research study, but not group consultation.

A statistical power analysis was performed to determine the sample size for noninferiority. Previous studies investigating risk recall suggested a mean recall of $25 \%$ to $80 \%$ for standard oral informed consent discussions; therefore, a mean recall of four of seven items and a standard deviation of 2.5 with a noninferiority limit of 2 was chosen $(2,8,25-27)$. With alpha 0.05 and power 0.95 , the projected sample size for the present study was 34 per study condition $(7,25)$.

The present study was approved by the institutional research ethics board and is a registered clinical trial (CDHA-RS/2014-244, ClinicalTrials.gov NCT02071238).

\section{Randomization and blinding}

When patients were contacted by the clinic administrator, they were screened for inclusion and exclusion criteria. If they met criteria for inclusion, they were randomly assigned to standard individual discussion or to an SMA, using Random.org's Random Integer Generator (https://www.random.org/integers). Patients were made aware of their assignment at the time and, if they did not wish to participate, were excluded from the study.

For the present study, all patients had an initial brief one-on-one meeting with the surgeon, during which the diagnosis was discussed. Medical history and demographic data, including sex, age, education and occupation, were collected using a standardized form. Willingness to participate in the study and lack of exclusion criteria were then confirmed. In total, this took approximately $8 \mathrm{~min}, 5 \mathrm{~min}$ for the initial medical discussion and 3 min for the study participation discussion.

Patients randomly assigned to the individual condition stayed in the same clinic room and the surgeon provided details of the potential risks and complications of the operation. A standardized script was used that included seven complications of open CTR, as compiled from review of the literature $(22,23,28,29)$ : not getting better; pain at site; bleeding; incision complications; infection; local nerve damage; and complex regional pain syndrome (CRPS). The script used plain language and an effort was also made to place equal emphasis on each potential risk during the discussion. Patients randomly assigned to the SMA had the same initial discussion with the surgeon to discuss the diagnosis and involvement in the study. Once a group of eight to 12 patients had met with the surgeon, they were then moved into a larger conference room and were presented the same script by the surgeon, with an accompanying visual presentation and time to allow for questions. SMAs lasted approximately $35 \mathrm{~min}$ to $45 \mathrm{~min}$, compared with $10 \mathrm{~min}$ to $20 \mathrm{~min}$ for an individual consultation, each in addition to the $5 \mathrm{~min}$ for initial discussion. Total surgeon time to conduct a consultation session 10 patients in the SMA condition ranged from $85 \mathrm{~min}$ to $95 \mathrm{~min}([10 \times 5 \mathrm{~min}]+[35 \mathrm{~min}$ to $45 \mathrm{~min}])$, while the time to see 10 patients in the individual condition ranged from $150 \mathrm{~min}$ to $250 \mathrm{~min}([10 \times[5+[10$ to $20 \mathrm{~min}])$.

Two weeks following the initial consultation, but before the time of surgery, a blinded member of the research team contacted each patient via telephone. Using a standardized script to minimize bias and avoid hints or cues, the patient was asked to recall the seven specific risks discussed at the initial consultation. In follow-up after surgery, patients were again contacted by a blinded member of the research team and asked to rate their overall satisfaction, comfort with the surgeon and satisfaction with surgeon on a 10-point Likert scale.

\section{Analysis}

Statistical analysis was performed using R (R Foundation for Statistical Computing, Austria). Mean risk recall, comfort and satisfaction for each group were compared using independent samples $t$ tests. Recall for individual risks was compared using a two-proportion Z-test. Demographic data were analyzed using an independent $t$ test for age, a 
TABLE 1

Demographic data of participants

\begin{tabular}{lccc}
\hline Characteristic & Individual $(\mathbf{n}=\mathbf{3 9})$ & SMA ( $\mathbf{n = 3 6 )}$ & $\mathbf{P}$ \\
\hline Age, years & & & 0.6689 \\
Mean & 56.0 & 54.9 & \\
Range & $32-75$ & $32-75$ & \\
Sex & & & 0.0628 \\
$\quad$ Male & $19(48.7)$ & $10(27.8)$ & \\
Female & $20(51.3)$ & $26(72.2)$ & \\
Level of education & & & 0.4827 \\
< High school & $7(17.9)$ & $3(8.3)$ & \\
High school & $16(41.0)$ & $11(30.6)$ & \\
College & $7(17.9)$ & $9(25.0)$ & \\
Undergraduate & $8(20.5)$ & $11(30.6)$ & \\
Graduate & $1(2.6)$ & $2(5.6)$ & \\
\hline
\end{tabular}

Data presented as $n$ (\%) unless otherwise indicated. There were no statistical differences in age, sex or education level. SMA Shared medical appointment

Z-test for sex and a Wilcoxon rank sum for education level. Pearson and Spearman correlations were used to correlate risk recall with age and education. Patients who could not be contacted for their initial telephone survey were not included in the analysis.

\section{RESULTS}

Demographics

Forty patients were recruited into each arm of the study starting in October 2014, with final follow-up in June 2015, but some were lost to follow-up. A total of 75 patients completed the study, with 39 in the individual consultation condition and 36 in the SMA condition. There was no significant difference in patient demographic data (Table 1).

\section{Risk recall}

There was no significant difference between the number of surgical risks recalled between the SMA and individual consult conditions $(2.06 \pm 1.15$ versus $1.64 \pm 1.04 ; \mathrm{P}=0.11)$ (Figure 2$)$. More participants in the SMA condition remembered the specific risks of infection and bleeding (61.1\% versus $33.3 \%$ [P=0.02]; 30.6\% versus $10.3 \%$ $[\mathrm{P}=0.028])$. Very few participants in either condition recalled CRPS (5.6\% versus $2.6 \% ; \mathrm{P}=0.51$ ) (Figure 3 ). Age did not influence the number of risks recalled (Pearson correlation $\mathrm{r}=0.074 ; \mathrm{P}=0.527$ ). However, the number of risks recalled was positively correlated with a higher level of education (Spearman rank correlation $r=0.236$; $\mathrm{P}=0.042$ ).

\section{Satisfaction}

There was no difference between SMA and individual consult conditions in overall satisfaction $(8.70 \pm 2.03$ versus $8.88 \pm 1.15 ; \mathrm{P}=0.747)$, satisfaction with the surgeon $(8.05 \pm 2.56$ versus $8.13 \pm 1.86 ; \mathrm{P}=0.920)$ or overall comfort $(8.80 \pm 2.02$ versus $8.31 \pm 1.89 ; \mathrm{P}=0.460)$.

\section{DISCUSSION}

SMAs for CTR consultation were not only noninferior to standard individual consultation, but patients who received their consultation as part of a group recalled certain risks better than their counterparts. This effect was observed without decreasing overall satisfaction, satisfaction with the surgeon or overall comfort.

The present study is concordant with previous findings that patients generally have a poor recall of the risks presented during their initial surgical consultation $(2,8,25,26)$. The specific risks recalled were not uniform, with a larger proportion of patients recalling 'not getting better' and 'infection', while very few remembered CRPS, a risk with some of the most severe long-term consequences. This trend may reflect that risks are more difficult to remember if they are difficult to conceptualize or are not common knowledge $(8,26)$. Poor risk recall

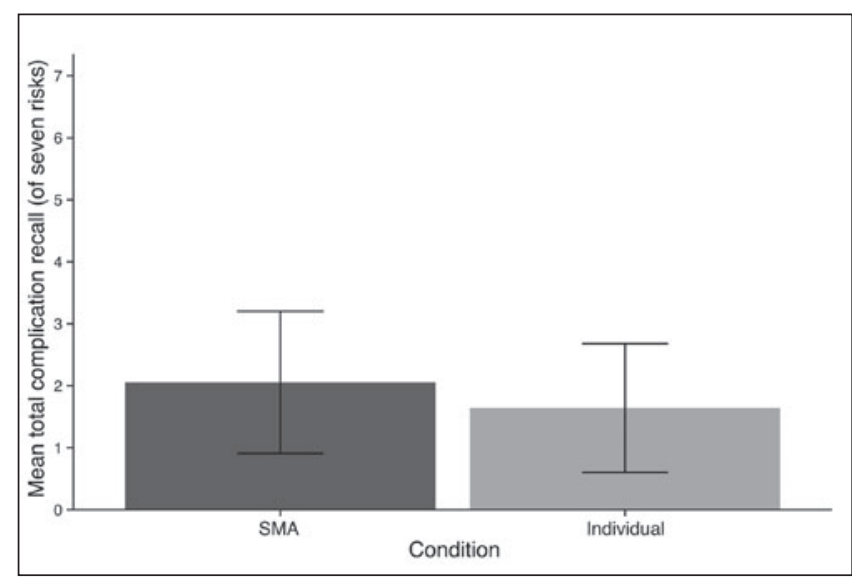

Figure 2) Mean ( $\pm S D$ ) number of seven surgical risks recalled between the group consult and individual consult conditions $(2.06 \pm 1.15$ versus $1.64 \pm 1.04 ; P=0.106)$. Individual Individual appointment; SMA Shared medical appointment

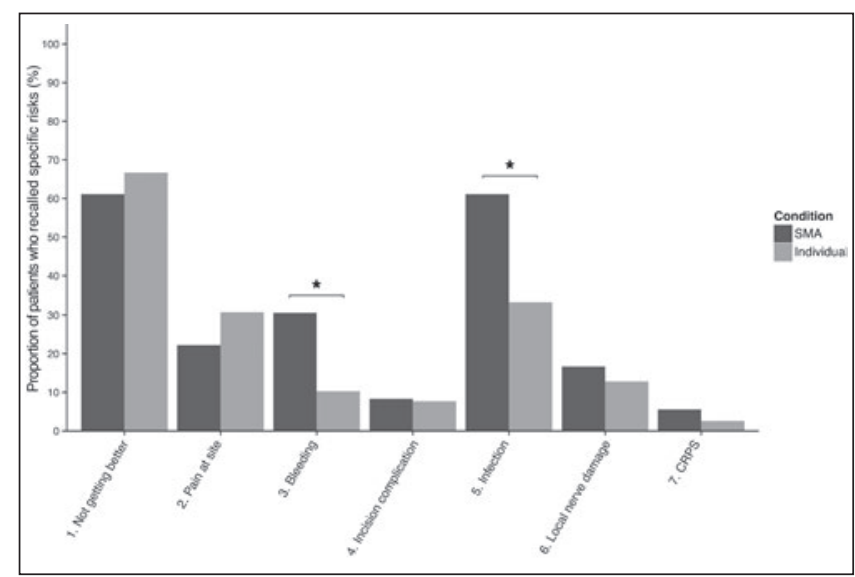

Figure 3) Proportion of patients who recalled specific risks: bleeding (30.6\% versus $10.3 \% ; P=0.028)$; infection $(61.1 \%$ versus $33.3 \%$; $P=0.02)$; and complex regional pain syndrome $(5.6 \%$ versus $2.6 \%$; $P=0.51)$. Asterisks indicate statisitcally significant differences (ie, $P<0.05)$. CRPS Complex regional pain syndrome; Individual Individual appointment; SMA Shared medical appointment

may also be driven by a limited appreciation of the potential severity of the risks because a positive correlation between level of education and number of risks recalled was observed without a significant effect of age $(25,26)$.

While patients in the SMAs did not perform statistically significantly better overall than patients who had their consultation individually, they did have improved recall of infection and bleeding risks. This increase may be due to two differences between the SMA and individual consultation, the first being that the SMA discussions were much longer ( $35 \mathrm{~min}$ to $45 \mathrm{~min}$ ) than individual discussions (10 $\mathrm{min}$ to $20 \mathrm{~min}$ ). Previous studies have shown that patient education sessions lasting $20 \mathrm{~min}$ to $30 \mathrm{~min}$ improve overall comprehension and risk recall because it enables patients to process information and prepare for the impact that the surgery may have $(2,8)$. The second difference is that patients receiving SMA consultation received a visual presentation, and audiovisual interventions in the informed consent process have consistently been shown to improve comprehension compared with standard oral discussion $(2,5)$. The initial sample size calculation overestimated the total number of risks that patients would recall as well as the standard deviation. Given a larger sample size, a more pronounced benefit of SMAs on recall may have been observed. 
The high level of comfort and satisfaction of patients who participated in SMAs is encouraging because these factors are correlated with decreased anxiety and improved health outcomes, and demonstrate that communication was perceived as adequate. Strong communication is an important part of the patient-physician relationship because it gives patients more realistic expectations, increases cooperation and may decrease malpractice liability $(1-4)$. When a patient experiences a complication that was undisclosed or even disclosed but not remembered, they may claim malpractice. Any nonstandardized method of disclosing surgical risks may expose the surgeon to litigation, especially because laws regarding informed consent are inconsistent across jurisdictions (5). This risk can be minimized by reducing variability in the informed consent discussion as was done in our study with the use of a standardized script for both individual and group consultations.

In addition to the benefits of improved risk recall and standardization, SMAs provide a means for improving clinic workflow. Clinic efficiency is becoming increasingly important as both the Joint Commission on Accreditation of Healthcare Organization and the National Surgical Quality Improvement Program are grading institutions and providers based on both patient satisfaction and financial efficiency (30). Thorough educational discussion with individual patients can take a significant length of time, having a negative impact on efficiency (2). Physicians must attempt to strike a balance between having briefer informed consent discussions, delaying other patients or seeing fewer patients per clinic. The length of time for each consultation in the present study was $5 \mathrm{~min}$ for the initial discussion of the condition and an additional $10 \mathrm{~min}$ to $20 \mathrm{~min}$ for the informed consent process in the individual consultation. amounting to approximately $150 \mathrm{~min}$ to $250 \mathrm{~min}$ to see 10 patients. To see the same number of patients in an SMA would only take $85 \mathrm{~min}$ to $95 \mathrm{~min}([10 \times 5 \mathrm{~min}]$ + [ $35 \mathrm{~min}$ to $45 \mathrm{~min}]$ ) and each patient would have a longer time with the surgeon. Fifteen minutes is a commonly reported surgical consultation time (6) and, while some surgeons may be able to conduct a faster consultation, shortening consultation time could affect patient understanding, information retention and satisfaction, because overall session length is strongly positively correlated with patient comprehension $(6,8,31)$.

The SMA model may further improve clinic efficiency if sessions are partially led by a nonphysician clinician, such as a nurse or physician assistant, freeing up additional physician time. The economic benefit has been shown in a wide variety of subspecialty clinics that implemented SMAs, showing not only better patient access and productivity, but also the potential for increased revenue $(12,20,32,33)$. While there is a chance of an initial disruption to clinic flow when this method of consultation is implemented, it can significantly increase efficiency once established (13). Similar to what was done in the present study, it is easiest to start with a condition that has a well known, objective measurement to allow for screening into an SMA before the first clinic visit. For conditions that are more variable, one approach is to stagger the bookings so that there is an initial block of time reserved for screening new patients followed by a set time for a group consultation. This method ensures that patients only require a single clinic visit, but also allows the patient to consider his or her options, and return to clinic at a later date to join one of the group discussions.

Despite the benefits of increased clinic efficiency and a trend toward improved risk recall, there is a fear that group consultation could weaken the patient-physician relationship, potentially decreasing satisfaction, trust and adherence to follow-up recommendations $(1,2)$. Patient satisfaction is a prerequisite of high-quality care, and satisfaction is an increasingly influential indicator for patients, insurers and accrediting bodies in selecting and grading health care providers and institutions $(4,30)$. Importantly, our study showed no difference in overall satisfaction, surgeon satisfaction and overall comfort between patients who received individual or group consultations.

Another potential argument against SMAs pertains to the risk of a confidentiality breach among patients in the group. The Health
Insurance Portability and Accountability Act (HIPAA) or local privacy regulations may be perceived as a barrier to the implementation of SMAs. However, there are no specific laws against patient-patient or patient-observer sharing of medical knowledge in Canada or the United States. By informing outside observers about medical standards of confidentiality and obtaining explicit patient agreement with respect to having an outside observer present, physicians will maintain the American Medical Association's (AMA) Code of Ethics (34). Similarly, legislative compliance can be maintained by having patients agree to protect the privacy of others by not identifying or discussing health problems outside the group. Patient agreement for both AMA and HIPAA stipulations is quickly formalized with a signed confidentiality agreement, as supported by HIPAA and professional organizations such as the American Academy of Family Physicians $(17,35,36)$.

A final ethical consideration is that physicians should avoid situations in which an outside observer's presence may negatively influence the medical interaction. Previous studies have found that rather than feeling coerced, patients respond positively to group education $(11,14,15,34)$. Although this was not quantified, many patients in the current study expressed a positive opinion of the process and of the patients screened for the study who declined participation, none stated potential involvement in an SMA as the cause.

The present study demonstrated that SMAs for surgical consultation were noninferior, if not superior, to standard individual consultation for surgical risk recall without negatively affecting patient satisfaction or comfort. Unfortunately, overall recall in both groups was poor, especially for significant but hard to conceptualize risks such as CRPS. This adds to the body of evidence that more than an oral discussion is needed, especially as better-informed patients have a improved understanding and therefore are less likely to pursue legal action (5). Other authors have proposed that additional tools should be implemented to further improve recall and comprehension of abstract concepts. For example, feedback techniques, increased use of multimedia and interactive computer programs, all of which could be more easily added to an SMA than an individual consultation $(2,4,5,9)$.

The intention of the present study was not to prove the superiority of SMAs, merely that they did not present any reduction in patient education, satisfaction or comfort compared with standard individual consultations, while providing a number of known workflow benefits $(10,17,18,37)$. It was, therefore, not sufficiently powered to detect more subtle but potentially clinically relevant benefits of SMAs. An added limitation is that risk recall does not perfectly equate to understanding and patient comprehension was not formally assessed (4). More comprehensive surveys may demonstrate differences in understanding beyond simple retention of a list of risks. While patient comfort and satisfaction were assessed using a simple Likert scale and not a validated survey, the results are consistent with other studies that have found high patient acceptance and willingness to participate $(10,11,17,18,20)$.

Based on these results, the authors recommend implementing SMAs for large-volume, low-variation, low-urgency surgery. SMAs can improve patient education and clinic flow, with very high patient satisfaction while providing equal or better outcomes in terms of risk recall. Concerns regarding patient confidentiality and HIPAA compliance can be overcome with the appropriate documentation to meet privacy regulations. Integration into existing clinic schedules can be accomplished with basic measures at the time of booking. Moving forward, SMAs and other forms of group education should be regarded as one of the many tools that can be used to help optimize the patient experience in an integrated fashion.

DISCLOSURES: The authors no financial disclosures or conflicts of interest to declare. 


\section{REFERENCES}

1. Bostick NA, Sade R, McMahon JW, Benjamin R, American Medical Association Council on Ethical and Judicial Affairs. Report of the American Medical Association Council on Ethical and Judicial Affairs: Withholding information from patients: Rethinking the propriety of "therapeutic privilege". J Clin Ethics 2006;17:302-6.

2. Schenker Y, Fernandez A, Sudore R, Schillinger D. Interventions to improve patient comprehension in informed consent for medical and surgical procedures: a systematic review. Med Decis Making 2011;31:151-73.

3. American Medical Association Council on Ethical and Judicial Affairs. Opinion 8.08. Informed Consent. 2006 <www.ama-assn.org/ ama/pub/physician-resources/medical-ethics/code-medical-ethics/ opinion808.page > (Accessed November 30, 2015).

4. Kessler TM, Nachbur BH, Kessler W. Patients' perception of preoperative information by interactive computer programexemplified by cholecystectomy. Patient Educ Couns 2005;59:135-40.

5. Leclercq WKG, Keulers BJ, Scheltinga MRM, Spauwen PHM, van der Wilt G-J. A review of surgical informed consent: Past, present, and future. A quest to help patients make better decisions. World J Surg 2010;34:1406-15.

6. Hall DE, Prochazka AV, Fink AS. Informed consent for clinical treatment. CMAJ 2012;184:533-40.

7. Lavelle-Jones C, Byrne DJ, Rice P, Cuschieri A. Factors affecting quality of informed consent. BMJ 1993;306:885-90.

8. Nadeau DP, Rich JN, Brietzke SE. Informed consent in pediatric surgery: Do parents understand the risks? Arch Otolaryngol Head Neck Surg 2010;136:265-9.

9. Mulsow JJW, Feeley TM, Tierney S. Beyond consent - improving understanding in surgical patients. Am J Surg 2012;203:112-20.

10. Stults CD, McCuistion MH, Frosch DL, Hung DY, Cheng PH, Tai-Seale M. Shared medical appointments: A promising innovation to improve patient engagement and ease the primary care provider shortage. Popul Health Manag 2016;19:11-6.

11. Knackstedt TJ, Samie FH. Shared medical appointments for the preoperative consultation visit of Mohs micrographic surgery. J Am Acad Dermatol 2015;72:340-4.

12. Fischer KL, Christman MS. Improving clinic productivity through a shared medical appointment. Urol Pract 2015;2:55-9.

13. Murray M, Berwick DM. Advanced access: Reducing waiting and delays in primary care. JAMA 2003;289:1035-40.

14. Platt J, Baxter N, Jones J, et al. Pre-consultation educational group intervention to improve shared decision-making in postmastectomy breast reconstruction: study protocol for a pilot randomized controlled trial. Trials 2013;14:199.

15. Causarano N, Platt J, Baxter NN, et al. Pre-consultation educational group intervention to improve shared decision-making for postmastectomy breast reconstruction: A pilot randomized controlled trial. Support Care Cancer 2015;23:1365-75.

16. Sikon A, Bronson DL. Shared medical appointments: Challenges and opportunities. Ann Intern Med 2010;152:745-6.

17. Kaidar-Person O, Swartz EW, Lefkowitz M, et al. Shared medical appointments: New concept for high-volume follow-up for bariatric patients. Surg Obes Relat Dis 2006;2:509-12.

18. Seesing FM, Drost G, Groenewoud J, van der Wilt G-J, van Engelen BG. Shared medical appointments improve QOL in neuromuscular patients: a randomized controlled trial. Neurology 2014;83:240-6.
19. Theobald M, McMullen S, Barnett D, Hughes C. A guide to group visits for chronic conditions affected by overweight and obesity. AAFP 2009.

20. Giladi AM, Brown DL, Alderman AK. Shared medical appointments for preoperative evaluation of symptomatic macromastia. Plast Reconstr Surg 2014;134:1108-15.

21. Fajardo M, Kim SH, Szabo RM. Incidence of carpal tunnel release: Trends and implications within the United States ambulatory care setting. J Hand Surg Am 2012;37:1599-605.

22. Shores JT, Lee WPA. An evidence-based approach to carpal tunnel syndrome. Plast Reconstr Surg 2010;126:2196-204.

23. Scholten RJPM, Mink van der Molen A, Uitdehaag BMJ, Bouter LM, de Vet HCW. Surgical treatment options for carpal tunnel syndrome. Cochrane Database Syst Rev 2007;CD003905.

24. Weiss MG, Ramakrishna J, Somma D. Health-related stigma: Rethinking concepts and interventions. Psychol Health Med 2006;11:277-87.

25. Hong P, Makdessian AS, Ellis DAF, Taylor SM. Informed consent in rhinoplasty: Prospective randomized study of risk recall in patients who are given written disclosure of risks versus traditional oral discussion groups. J Otolaryngol Head Neck Surg 2009;38:369-74.

26. Makdessian AS, Ellis DAF, Irish JC. Informed consent in facial plastic surgery: Effectiveness of a simple educational intervention. Arch Facial Plast Surg 2004;6:26-30.

27. Chan Y, Irish JC, Wood SJ, et al. Patient education and informed consent in head and neck surgery. Arch Otolaryngol Head Neck Surg 2002;128:1269-74.

28. Benson LS, Bare AA, Nagle DJ, Harder VS, Williams CS, Visotsky JL. Complications of endoscopic and open carpal tunnel release. Arthroscopy 2006;22:919-24.

29. Gerritsen AAM, de Vet HCW, Scholten RJPM, Bertelsmann FW, de Krom MCTFM, Bouter LM. Splinting vs surgery in the treatment of carpal tunnel syndrome: A randomized controlled trial. JAMA 2002;288:1245-51.

30. Harnett MJP, Correll DJ, Hurwitz S, Bader AM, Hepner DL. Improving efficiency and patient satisfaction in a tertiary teaching hospital preoperative clinic. Anesthesiology 2010;112:66-72.

31. Schenker Y, Fernandez A, Sudore R, Schillinger D. Interventions to improve patient comprehension in informed consent for medical and surgical procedures: A systematic review. Med Decis Making 2011;31:151-73.

32. Sidorsky T, Huang Z, Dinulos JGH. A business case for shared medical appointments in dermatology: Improving access and the bottom line. Arch Dermatol 2010;146:374-81.

33. Noffsinger EB. Will drop-in group medical appointments (DIGMAs) work in practice. Perm J 1999.

34. American Medical Association Council on Ethical and Judicial Affairs. Opinion 5.0591. Patient Privacy and Outside Observers to the Clinical Encounter. 2005 <www.ama-assn.org/ama/pub/ physician-resources/medical-ethics/code-medical-ethics/ opinion50591.page> (Accessed January 3, 2016).

35. HIPAA. Incidental Uses and Disclosures. 2002 <www.hhs.gov/ hipaa/for-professionals/faq/incidental-uses-and-disclosures> (Accessed January 3, 2016).

36. Theobald M, McMullen S, Barnett D, Hughes C. A guide to group visits for chronic conditions affected by overweight and obesity. AAFP, 2009.

37. McCuistion MH, Stults CD, Dohan D, Frosch DL, Hung DY, Tai-Seale M. Overcoming challenges to adoption of shared medical appointments. Popul Health Manag 2014;17:100-5. 


\title{
PulsusEdit $^{\mathrm{m}}$
}

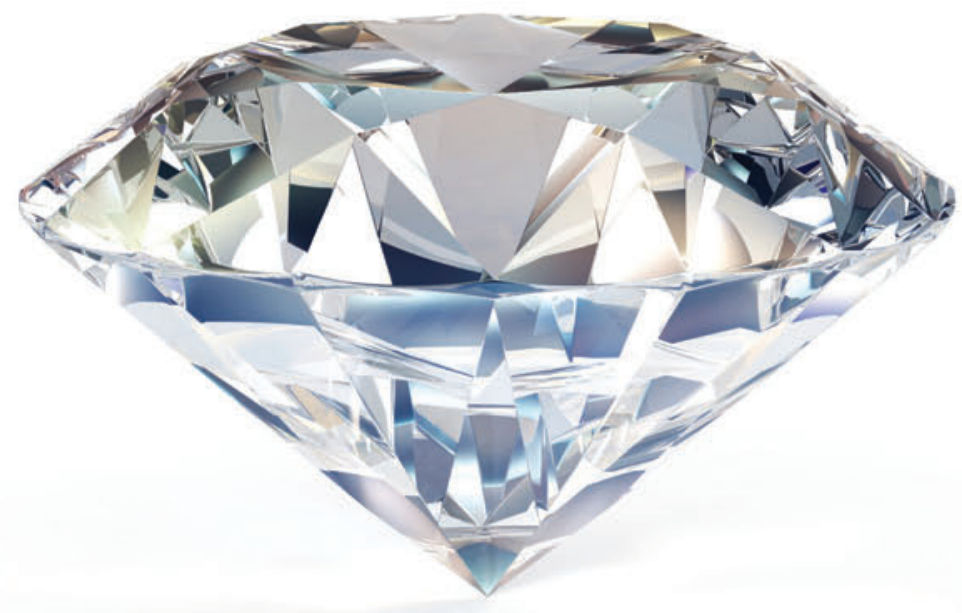

\section{Polish to Perfection}

\author{
Improve Your Manuscript \\ Get Published
}

www. PulsusEdit.com

PulsusEdit ${ }^{\text {TM }}$ specializes in high-quality editing of medical research manuscripts and is committed to providing you with industry-leading quality and service.

Visit PulsusEdit.com and submit your manuscript online for a no-obligation quote today! 